\title{
Complete Branchial Fistula : Five Case Series In A Rural Area Of Ahmednagar District
}

\author{
Dr.Kishve S.P ${ }^{1}$,, Dr.Kishve P.S ${ }^{2}$,Dr.Shinde K.J ${ }^{3}$.,Dr.Aniket Lathi ${ }^{4}$, \\ Dr.Anand Chava ${ }^{5}$, Dr. Syed Imdad ${ }^{6}$ \\ ${ }^{1}$ (Professor,Dept. Of E.N.T.Rural Medical College, Loni,India.) \\ ${ }_{2}^{2}$ (Associate Professor, Dept.Of Anatomy Rural Medical College, Loni,India.) \\ ${ }^{3}$ (Professor,Dept. Of E.N.T.Rural Medical College, Loni,India.) \\ ${ }^{4}$ (Assistant Professor,Dept. Of E.N.T.Rural Medical College, Loni,India) \\ ${ }_{5}^{5}$ (Assistant Professor,Dept. Of E.N.T.Rural Medical College, Loni,India.) \\ ${ }^{6}$ (Post Graduate Resident, Dept. Of E.N.T.Rural Medical College, Loni,India.)
}

\begin{abstract}
Objective: This is a report of 5 cases of complete second branchial fistula which were diagnosed and treated in a span of 2 years in the Department of ENT, head \& neck surgery, Rural Medical College, Loni. The main objective of this report is to highlight the use of fistulogram for the diagnosis. Case report: 5 cases were reported of the age group between 11 to 22 years who presented with an intermittent mucoid discharge from an external opening in the neck since birth with right to left ratio being 4:1 and male: female ratio being 1.5:1 \& were diagnosed to have a second branchial cleft fistula. A preoperative fistulogram revealed the tracts up to the tonsillar fossa. Complete excision of the tracts were done by a two step neck incision. Conclusion: Though second branchial fistulae are common, complete fistulae are rare and this merits the publication of this report. The report also stresses on the need to perform a preoperative fistulogram for the diagnosis.
\end{abstract}

Keywords: Branchial cleft, Branchial fistula, Complete second Branchial fistula, Management .

\section{Introduction}

Congenital cervical cysts, sinuses, and fistulae must be considered in the diagnosis of head and neck masses in children and adults. Anomalies of the second branchial fistula account for $90 \%$ of the developmental abnormalities of the branchial apparatus. Branchial fistula usually present in childhood as a weeping defect along the anterior border of sternocleidomastoid muscle at the junction of middle $\&$ lower $1 / 3^{\text {rd }}$ of neck and extends up through neck to end in tonsillar fossa / pillars. This is a report of 5 cases of complete second branchial cleft fistulae.

\section{Methodology :}

These case studies were carried out in Out Patient Department of Otorhinolaryngology, head and neck surgery, Pravara Rural Hospital, Loni Ahmednagar in a span of 2 years from 2010 to 2012

\section{Case Series of 5 cases :}

5 cases were reported to our ENT OPD in the age group between 11 to 22 years with male: female ratio being 1.5:1 \& right:left side ratio being 4:1. All these patients presented to our out patient clinic with history of small opening in the lower part of their neck since birth and intermittent, yellowish white discharge from the opening. Discharge from sinus opening was associated with fever in one of the case. On examination, a small opening was seen on neck along the anterior border of the sternomastoid at junction of middle and lower $1 / 3 \mathrm{rd}$ with scanty mucous discharge on pressure. In one of the case, margins of the sinus opening were inflamed with active mucopurulent discharge. (Fig 1) 


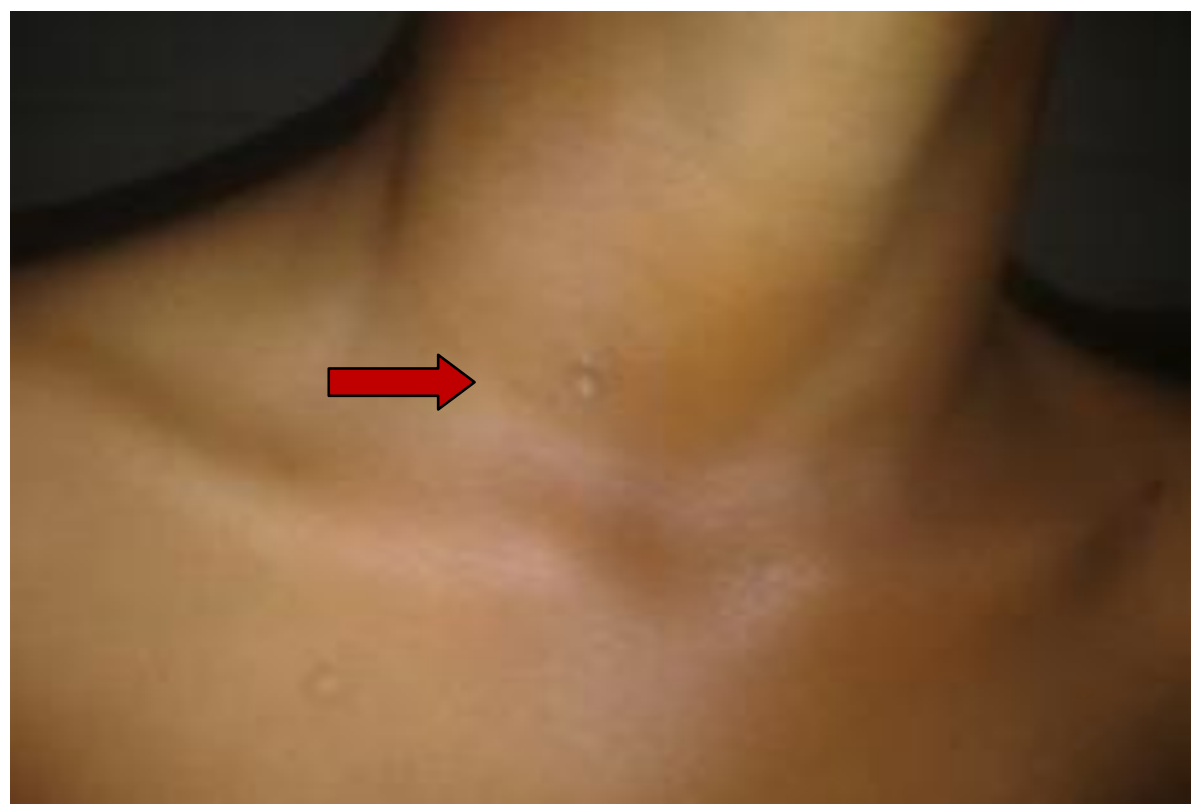

figure 1

On clinical examination of the oropharynx, it did not reveal any visible opening at the posterior tonsillar pillar. On the basis of clinical examination they were diagnosed to have a branchial fistula. A fistulogram showed the tract extending from the neck until the tonsillar region. Dye was seen entering the lateral wall of the Oropharynx in the tonsillar region.( AP and Lateral view) ( Fig 2 )

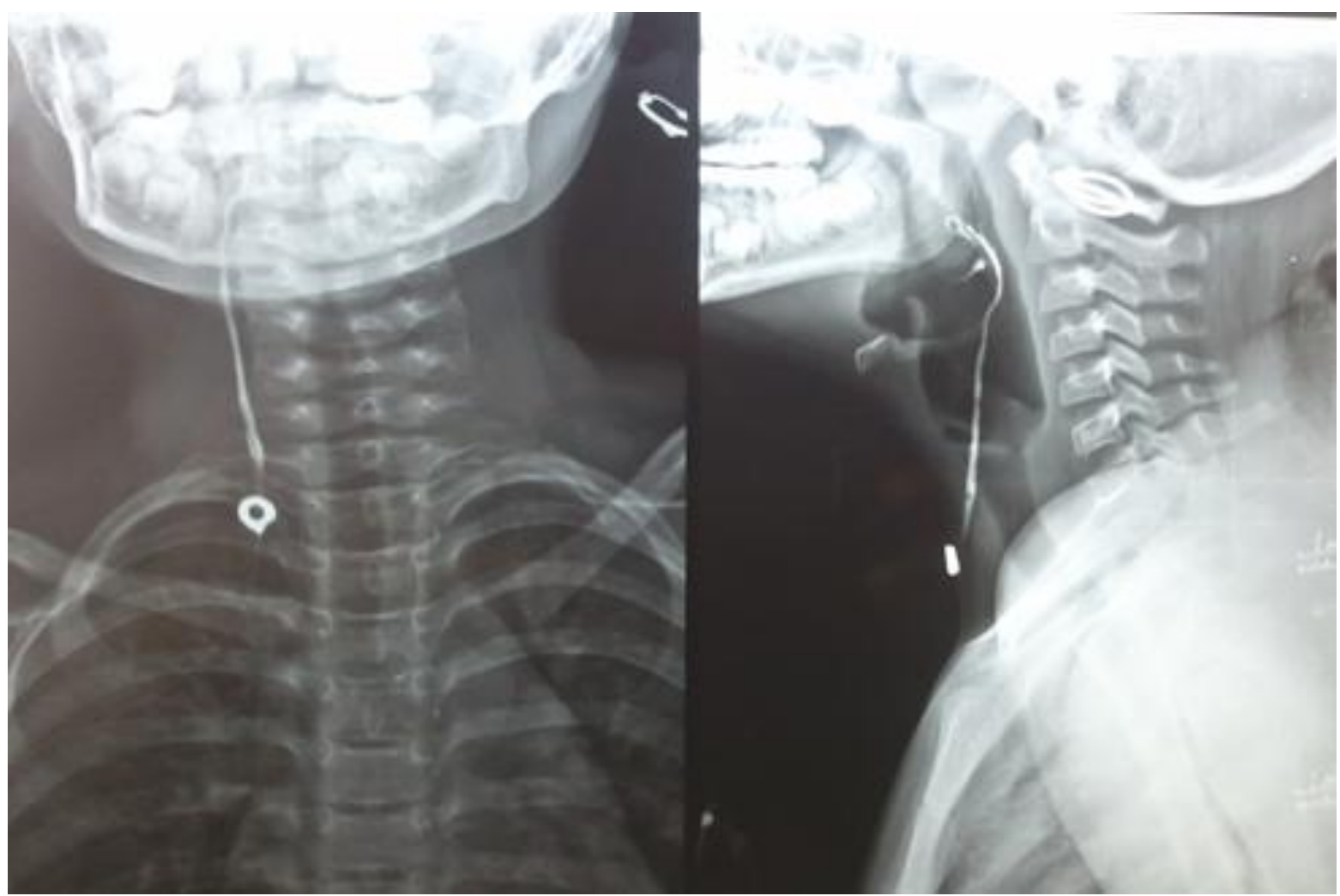

figure 2

After necessary investigations to confirm the surgical fitness, excision of the tract was carried out under general anaesthesia. Aim of surgery was complete excision of fistulous tract with tonsillectomy. Step ladder dissection was performed by combined approach via transcervical and transoral approach under general anaesthesia . 
First incision taken at the site of fistulous opening. The fistulous tract was then separated from skin and fascia over it. Second incision (Stepladder dissection ) was taken at the level of hyoid bone and fistulous tract was pulled through second incision to carry out further dissection towards oropharynx .Inspection of Oropharynx was then done and tonsil excised with attached fistulous tract. ( Fig 3 )

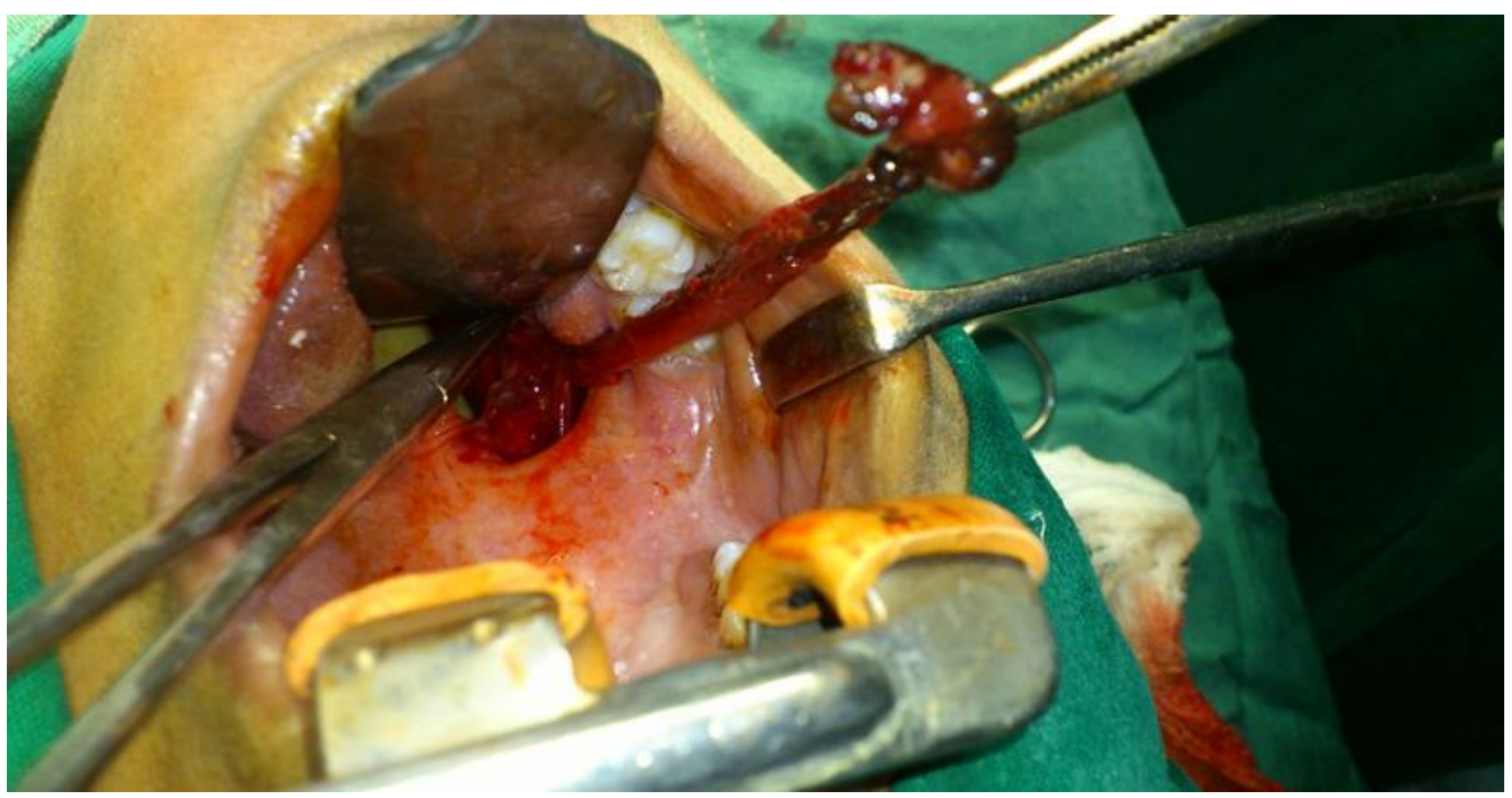

figure 3

Excised Fistulous tarct ( Fig 4 )

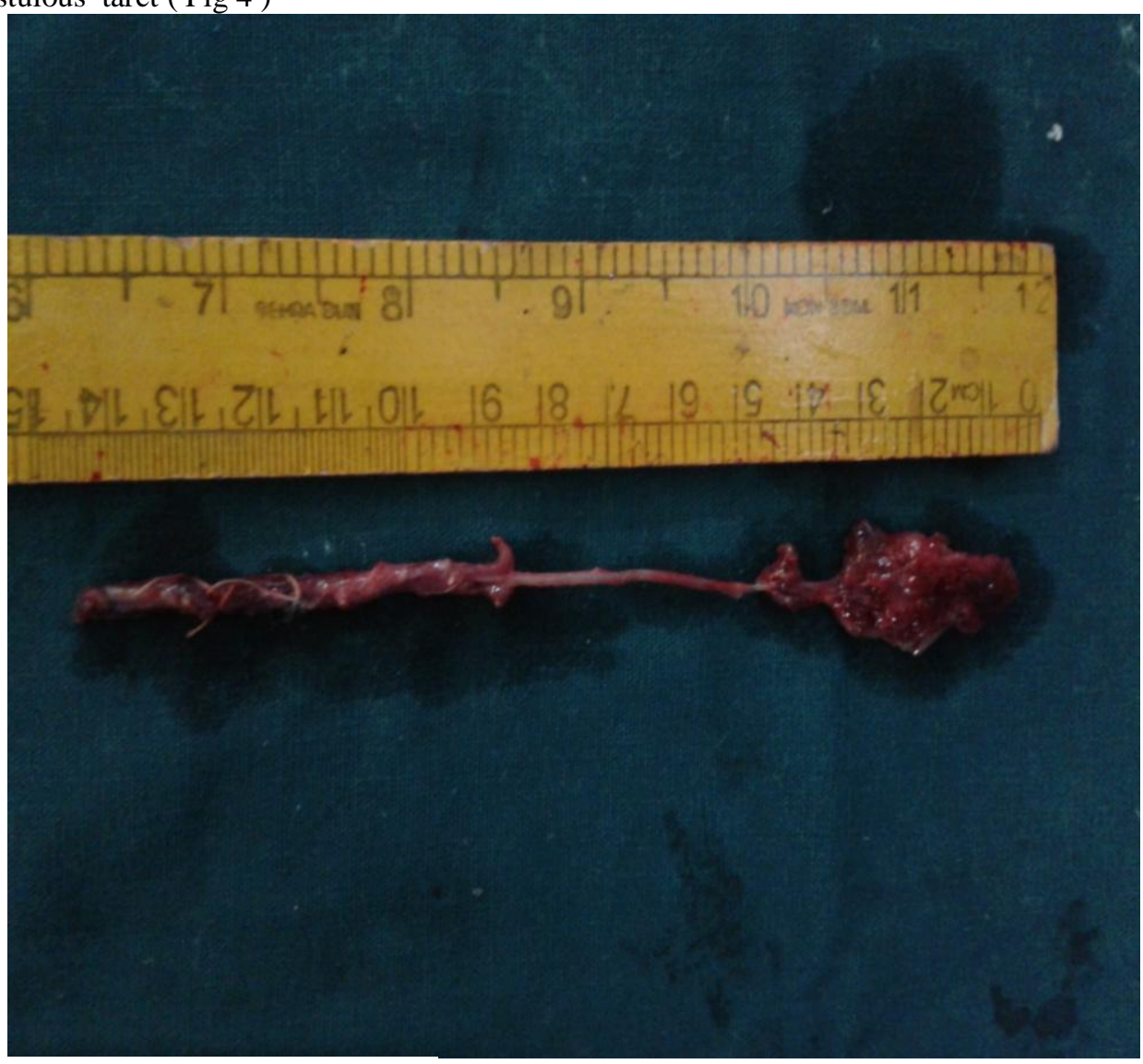

figure 4 
Histopathological examination confirmed the keratinized squamous epithelial lining of the tract with clusters of mucous secreting glands at places. No recurrence of symptoms is seen after 24 months of follow-up.

\section{Discussion}

Branchial cleft cysts arise from the failure of the pharyngobranchial ducts to obliterate durinf foetal development. They most frequently present in late childhood or early childhood, when the cysts become infected - usually after an upper respiratory tract infection. A branchial cleft cyst appears as a tender, inflammatory mass located at the anterior border of the sternocleidomastoid muscle. Branchial cleft cysts fall into three categories : first, second and third branchial cleft anomalies. First branchial cleft anomalies make up less than $1 \%$ of all branchiogenic anomalies and usually appear on the face or near the auricle.There are two types of first branchial anomalies, Type I and Type II . Type I first branchial cleft cysts are duplication anomalies of the external canal and are composed of ectodermally derived tissue. They may pass into the parotid gland and close to the facial nerve.Type II anomalies may comprise ectodermally and mesodermally derived tissues. These lesions typically present below the angle of mandible,pass through the parotid gland in close proximity to the facial nerve, and end either inferior to the external auditory canal or into the canal at the bony cartilageneous junction. Second branchial cleft anomalies are the most common of all the three types. They present as discrete, rounded masses below the angle of mandible and at the anterior border of the sternocleidomastoid muscle .The potential tract of an associated sinus passes deep to the second arch structures and superficial to the third arch derivatives, opening into the tonsillar fossa. Third branchial cleft cysts present anterior to the sternocleidomastoid muscle and lower in the neck than either first or second branchial cleft anomalies .Third branchial cleft cysts are deep to the third arch derivatives and superficial to fourth arch derivatives. These anomalies end in the pharynx at the thyrohyoid membrane or pyriform sinus. The management of branchial cleft anomalies is initial control of infection followed by surgical excision of the cyst and tract. As a general rule, incision and drainage procedures should be avoided ;however they may be necessary for acute abscess treatment before definitive excision. Needle aspiration and decompression can be beneficial in preventing incision and drainage, which increases the difficulty of definitive excision ${ }^{1}$.

A recent paper ${ }^{2}$ suggests that fourth branchial cleft fistulae arise from the ultimobranchial body and hance extend from the pharynx to the thyroid.

In another study ${ }^{3}$ a complete branchial fistula case was reported, diagnosed using fistulogram and a CT fistulogram and was completely excised.

In an Indian study ${ }^{4}$ a case of complete branchial fistula was diagnosed using fistulogram and complete tarct was excised using step ladder incisions and tonsillectomy.

In a study ${ }^{5}$ conducted at All India institute of Medical sciences New Delhi, case of complete branchial fistula with internal and external opening was excised using combined transcervical and transoral approach under general anaesthesia.

\section{Conclusion}

Complete branchial fistula arising from second branchial cleft is rare. It is not possible to excise the complete branchial fistula totally with transcervical approach only. This is a case series of complete branchial fistulae, which were managed through combined approach using transcervical route and transoral route. Complete branchial fistulae'are better managed by otolaryngologists who are capable of performing the combined approach.

\section{References}

[1]. Anil K. Lalwani Current Diagnosis and Treatment Otolaryngology Head and neck surgery chapter 27 page 418-419.

[2]. Nicolas R, Ducroz V, Garabedian EN, Triglia JM, Fourth Branchial pouch anomalies : a study of six cases and review of literature . International Journal of Paediatric Otorhinolaryngology . $1998 ; 44: 5-10$.

[3]. Wg C dr Samaresh Sahu, Wg Cdr Ameet Kumar, gp Capt TS Ramakrishnan Branchial fistula : an imaging perspective, MJAFI $2011: 67: 262-264$.

[4]. C. Shekhar, R. Kumar, R. Kumar, S.K. Mishra ,M. roy ,K. Bhavana The complete branchial fistula : A case report, Indian journal of otolaryngology and Head and neck Surgery Vol . 57, No. 4 October- December 2005.

[5]. Chava Anjaneyulu, Chakkyath Jayaram Sharan, Complete branchial fistula , Bahrain Medical Bulletin , Vol .25 ,No. 4, December 2003 . 